\title{
EKSPLORASI PENGALAMAN KELUARGA DALAM PERAWATAN PASIEN SKIZOFRENIA DI KALIMANTAN BARAT
}

\author{
(EXPLORATION OF FAMILY EXPERIENCE IN THE TREATMENT \\ OF SCHIZOPHRENIC PATIENTS IN WEST KALIMANTAN)
}

\author{
Fathur Mahali*, Djoko Priyono**, Ichsan Budiharto*** \\ * Mahasiswa Prodi Keperawatan Fakultas Kedokteran Universitas \\ Tanjungpura, Pontianak mahalifathur15@gmail.com **Dosen Keperawatan \\ Fakultas Kedokteran Universitas Tanjungpura, Pontianak djokopri07@ gmail.com \\ ***RSUD Dr. Soedarso, Pontianak Ichsanbudiharto@ gmail.com
}

\begin{abstract}
ABSTRAK
Latar Belakang : Gangguan jiwa jenis skizofrenia merupakan penyakit jiwa kronik yang berarti bisa pulih tetapi sangat berisiko tinggi untuk kambuh. Peran keluarga sebagai caregiver sangat diperlukan karena keluarga memiliki tanggungjawab dalam menangani dan memberikan perawatan secara langsung kepada pasien skizofrenia dalam segala situasi.

Metode : Penelitian kualitatif deskriptif menggunakan metode wawancara indepth interview dengan pendekatan fenomenologi. Penelitian dilakukan dengan 5 partisipan yang berperan sebagai caregiver bagi penderita skizofrenia di Kota Singkawang. Pengambilan sampel menggunakan purposive sampling. Pernyataan partisipan dicatat dengan menggunakan perekam suara, dan kemudian ditranskipkan, dikodekan, ditafsirkan, dan dikategorikan, sehingga dapat membentuk tema.

Hasil : Terdapat empat tema, yang pertama yaitu kasih sayang keluarga sebagai kunci perawatan yang efektif yang terdiri dari 3 kategori yaitu kelembutan, kontrol obat dan ketelatenan, tema yang kedua adalah upaya pencegahan kekambuhan dengan pengenalan gejala awal skizofrenia yang terdiri dari 2 kategori yaitu gejala positif dan gejala negatif, tema yang ketiga adalah beban psikologis yang dialami keluarga yang terdiri dari 2 kategori yaitu perasaan dan tindakan dan tema yang keempat adalah koping keluarga terhadap stigma sosial.

Kesimpulan : Pengalaman keluarga sangat berarti dalam meningkatkan kualitas hidup pasien skizofrenia dan untuk mengurangi resiko terjadinya kekambuhan. Kasih sayang yang diberikan keluarga dalam merawat penderita ternyata memberikan dampak yang sangat baik bagi penderita, karena dengan kasih sayang itu dapat membuat penderita merasa lebih baik.
\end{abstract}

Kata kunci : skizofrenia, pengalaman keluarga, perawatan 


\begin{abstract}
Background: Schizophrenic type of mental disorder is a chronic mental illness which means it can recover but has a very high risk for recurrence. The role of the family as a caregiver is very necessary because the family has the responsibility in handling and providing care directly to patients with schizophrenia in all situations.

Method: Descriptive qualitative research used in-depth interview method with a phenomenological approach. The study was conducted with 5 participants who acted as caregivers for schizophrenics in Singkawang City. Sample taking used purposive sampling. Participant statements are recorded using a voice recorder, and then transcribed, coded, interpreted, and categorized, so they can form a theme.

Results: There are four themes, the first is family affection as the key for effective treatment which consists of 3 categories, namely softness, drug control and patience, the second theme is prevention of recurrence by recognizing the initial symptoms of schizophrenia which consists of 2 categories namely positive symptoms and negative symptoms, the third theme is the psychological burden experienced by the family which consists of 2 categories, namely feelings and actions and the fourth theme is family coping with social stigma.

Conclusion: Family experience is very meaningful to improve the quality of life for schizophrenic patients and to reduce the risk of recurrence. The affection given by the family in treating the schizophrenics turns out to have a very good impact on the sufferers, because with affection it can make schizophrenics feel better.
\end{abstract}

Keywords: schizophrenia, family experience, treatment 


\section{PENDAHULUAN}

Angka kekambuhan skizofrenia yang terjadi berdasarkan hasil studi pendahuluan yang dilakukan di Rumah Sakit Jiwa (RSJ) Provinsi Kalimantan Barat didapatkan persentase kekambuhan yang terjadi pada tahun 2018 adalah sebesar 71,16 \% dengan jumlah pasien yang disebut sebagai pasien lama atau pasien yang sering mengalami kekambuhan sebanyak 1.034 orang, sedangkan pasien skizofrenia yang mendapatkan rawat inap di tahun 2018 adalah sebanyak 1453 orang $^{1}$.

Pihak RSJ yang dipimpin oleh Pak Suni selaku Direktur RSJ mengatakan bahwa umumnya pasien yang mendapatkan perawatan di RSJ adalah yang mengalami gangguan jiwa berat ${ }^{2}$. Riskesdas (2017) mengatakan prevalensi gangguan jiwa sekitar $1 \%$ dari jumlah penduduk ${ }^{3}$. Hasil pengamatan ini didukung dengan pernyataan dari Direktur RSJ Kalimantan Barat yang mengatakan bahwa : "Jika dilihat jumlah dari penduduk Kalbar adalah sekitar 5 juta jiwa, dilihat dari indikator hasil riset menyatakan bahwa ada sekitar 5.000 penderita gangguan jiwa di Kalbar. 5.000 penderita yang teridentifikasi gangguan jiwa ini, ada 10\% yang memang perlu pengangan segera karena masuk pada gangguan jiwa berat"2.

Pihak RSJ mengatakan ada sekitar 2.000 masyarakat Kalbar yang sering berkunjung ke RSJ Kalbar, termasuk dengan pasien lama yang sudah datang berkali-kali. Catatan rekam medik di RSJ sudah mencapai 6.000-an, hal ini membuktikan bahwa banyaknya masyarakat di Kalimantan Barat yang mengalami gangguan jiwa. Gangguan jiwa yang paling umum di jumpai adalah dengan diagnosa skizofrenia ${ }^{2}$.

Gangguan jiwa jenis skizofrenia ini merupakan penyakit jiwa kronik yang berarti bisa pulih tetapi sangat berisiko tinggi untuk kambuh kembali. Kekambuhan yang terjadi pada pasien dapat memberikan dampak buruk bagi beberapa pihak. Dampak buruk kekambuhan bagi keluarga yaitu menambah beban keluarga dari segi biaya perawatan dan beban mental karena anggapan negatif masyarakat kepada pasien, pasien sulit diterima oleh lingkungan atau masyarakat sekitar. RSJ juga akan terbebani karena bertambahnya pasien yang dirawat ${ }^{4,5}$.

Keluarga yang menjadi caregiver memiliki tanggung jawab penting dalam proses perawatan di rumah sakit, persiapan pulang, dan perawatan di rumah (continum of care). Peran keluarga sebagai caregiver sangat penting dalam menangani dan mencegah kekambuhan karena mereka bertanggung jawab memberikan perawatan secara langsung kepada pasien skizofrenia dalam segala situasi

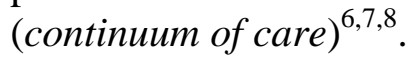

Orang dengan skizofrenia tidak bisa menjalankan kehidupan seharihari secara mandiri karena mengalami keterbatasan beraktivitas, berperilaku menyimpang, dan membutuhkan bantuan hampir diseluruh kegiatan dalam hidupnya sehingga sangat memerlukan dukungan keluarga sebagai caregiver. Peran keluarga sebagai caregiver sangat diperlukan 
dalam menangani dan mencegah gejala kekambuhan karena mereka bertanggung jawab memberikan perawatan secara langsung kepada pasien skizofrenia dalam segala situasi (continuum of care) ${ }^{9,10}$.

Keluarga yang berperan sebagai caregiver juga merupakan individu yang paling dekat dengan pasien skizofrenia, sehingga dapat mengetahui kondisi pasien secara keseluruhan dan dapat memberikan gambaran serta uraian terkait kondisi pasien sebelum dan sesudah mengalami kekambuhan. Keluarga juga berperan terhadap pengobatan dan kesembuhan pasien gangguan jiwa. Jika tidak ada dukungan keluarga, maka penderita tidak dapat berperan sesuai harapan lingkungannya, sehingga apabila pasien dinyatakan sembuh dan kembali ke lingkungannya terutama keluarga akan kembali dirawat dengan alasan perilakunya tidak diterima keluarga dan lingkungannya. Semua itulah yang menyebabkan perlunya edukasi kepada pihak keluarga terkait perawatan pada penderita skizofrenia agar terhindar dari resiko kekambuhan ${ }^{11,12}$.

Keluarga juga berperan dalam pengelolaan lingkungan sosial bagi pasien skizofrenia, karena lingkungan sosial yang baik dan nyaman adalah lingkungan yang sangat diperlukan oleh pasien yang telah dinyatakan pulih karena skizofrenia dengan harapan dapat kembali bersosialisasi dan beraktivitas dengan baik seperti dulu. Namun yang menjadi permasalahan saat ini adalah kurangnya pengetahuan dan pemahaman caregiver terkait perawatan pasien gangguan jiwa.

Anggota keluarga yang berperan sebagai caregiver, tentunya mempunyai peran yang sangat sentral agar dapat merawat pasien skizofrenia di rumah dengan baik. Menurut beberapa penelitian ditemukan beberapa faktor caregiver yang berhubungan dengan kekambuhan pasien skizofrenia antara lain faktor pengetahuan dan dukungan (support), kualitas hidup dan peristiwa hidup yang penuh stress selama merawat pasien ${ }^{13,14}$.

\section{METODE}

Metode penelitian yang digunakan adalah metode penelitian kualitatif dengan pendekatan fenomenologi. Partisipan dalam penelitian ini adalah keluarga yang memberikan perawatan kepada penderita skziofrenia di rumah. Partisipan dalam penelitian ini didapatkan sebanyak 5 orang. Teknik pengambilan sampel dalam penelitian ini adalah teknik purposive sampling. Purposive sampling merupakan pemilihan partisipan berdasarkan maksud dan tujuan penelitian oleh peneliti. Teknik pengambilan data yang digunakan pada penelitian kualitatif ini dimulai dengan menentukan kriteria inklusi, kemudian sampel diseleksi dan ditetapkan. Kriteria dalam penelitian ini anggota keluarga yang memberikan perawatan pada penderita di rumah. Pengumpulan data pada penelitian ini dengan melakukan in depth interview dengan 5 partisipan. Wawancara yang dilakukan pada partisipan dengan 
tujuan untuk menganalisis dan mengeksplorasi pengalaman keluarga dalam memberikan perawatan pada penderita skziofrenia di rumah. Analisa data yang digunakan dalam penelitian ini terdiri dari 3 langkah yang pertama yaitu abstraksi data adalah proses merangkum untuk itu maka perlu dicatat secara teliti dan rinci hasil dari wawancara (membuat transkip wawancara). Mengabstraksi data berarti merangkum, memilih halhal pokok, memfokuskan pada hal-hal yang penting, pemberian coding, mencari tema dan pola data yang diperoleh. Kedua, interprestasi data yang merupakan penyajian data dengan menggunakan metode deskriptif, yaitu menggambarkan tema-tema yang sudah didapat dengan bentuk tulisan. Ketiga, penarikan kesimpulan adalah dari data yang diperoleh, kemudian dikategorikan, dicari tema dan polanya kemudian ditarik kesimpulannya

\section{HASIL}

Penelitian ini dilaksanakan pada bulan Mei sampai dengan Juli 2019. Penelitian dilakukan pada 5 partisipan yang merupakan keluarga yang memberikan perawatan kepada penderita skziofrenia di rumah. Penderita skziofrenia merupakan pasien rawat jalan di Rumah Sakit Jiwa Provinsi Kalimantan Barat. Data diperoleh dari hasil wawancara sebagai berikut;

\section{Kasih Sayang Keluarga Sebagai Kunci Perawatan yang Efektif}

P1 :" ...yaa... harus pelan tidak boleh kasar",

"...letakkan di tangannya setelah itu suruh minum udah di masukkan ke mulut, diperiksa lagi siapa tau ada di bawah lidah tidak ditelan"

"...beri dia aktivitas yang pastinya membantu dirumah seperti menyapu, mengepel, atau kegiatan lain yang bisa mengalihkan penyakitnya"

P2 :"...biase sih memang harus nak pelan giye be ii, ndak boleh di bentakbentak ye harus nak pelan geye merawatnye maklom lah urang gangguan jiwa giye harusnye, harus pelan, kasar die dah daan bise inyan sekali geye"

"...biase saye barek ke tangannye barok saye suruh pinum, tapi saye ndak jauh dari sie ade saye ngeliat giye, biase kan... biase katenye perawat kan katenye pasien kan jak rasenak aneh geye be biase ndak di telannye taroknye bawah lidah kan barok di bilangnye udah di telan, jadi saye bilang buka lidah di bukanye... oo udah ditelan geye"

"...ade sih, saye suruh tah eee... maklomlah iii kite di sitok kan jak daan kerje, kerje jak di pulau iee, kerjaan jak di pulau semue-semuenye. Jadi saye suruh biasenye nyapu, ngape geye be nyapu bekemas-kemas geye lah bantu-bantu giye, paling giye lah nyuruh-nyuruh giye, tapi be pun die betol be maok die, tapi pun dah daan betol daan tedudok melamun geye jadi pun dah kite suruh sekali dua kali die daan maok begerak udah biarkan ajak geye"

P3 :" ...eee.... kita harus sabar dengan die, misalkan apa.. kalau kita keras 
sama die die bakalan lebih keras agek"

'...di kasihkan jak lah tiap habis die makan, terus ditanya udah makan obat ke belum"

"...kakak kasik kegiatan cuci piring, nyapu, ngepel”

P4 :"...ya biasa sih eee.. tidak boleh kasar pelan-pelan memberitahu dia dan harus memberikan memberikan masukan yang bermanfaat untuk dia”

"...cara memberikan obat kepada mereka yaitu pertama-tama obat dibuka dari plastiknya setelah itu memberikan ke tangannya setelah itu menyuruh dia minum, untuk memastikan obat itu udah ditelan atau belum disuruh buka mulut naekkan keluarkan lidahnya dan di angkat naik lidah jadi dibawah itu kadang ada yang menyembunyikan di bawah lidah akhirnya obat itu tidak ditelan"

"...berusaha untuk mengurangi beban fikirannya yang digunakan misalnya itu mengalihkan perhatiannya, biasanya dibawa nonton tv atau menyapu dan mengepel menyiram bunga"

P5 :"...itu kan kadang die kan mau lawan gitu ya misalnya kita juga ya gimana ya namanya juga orang gitu kadang juga suara kita agak keras juga kan kita dari pertama kan kita ngomong sama dia misalnya kan gimana gimana gitu bandingbandingkan sama orang gitu ya, saat kita ngomong gitu kadang di dengar tapi kadang ndak bisa di tanggapi" “...iyelah ketangannya gitu biasa, pernah juga dulu kan sering ndak mau makan obat kita masukkan ke mulutnya juga pernah", “...suruh kerja apa gitu ye, misalnya nyapu lah gitu, cuci piring kalau lagi mood nya bagus maok die"

Tema ini disusun berdasarkan adanya sub kategori kelembutan, kontrol obat dan ketelatenan keluarga dalam memberikan perawatan pada penderita skizofrenia di rumah. Pernyataan partisipan di atas mengenai cara memberikan perawatan pada penderita skizofrenia di rumah haruslah dengan kelembutan, dengan artian harus pelan tidak boleh kasar. Selain itu keluarga juga harus melakukan pengontrolan dalam pemberian obat dengan maksud keluarga dapat memastikan penderita skizofrenia memang benar-benar meminum obat tersebut di waktu yang tepat, serta ketelatenan keluarga dalam mengarahkan dan memberikan aktivitas kepada penderita skziofrenia agar penderita dapat berolahraga dan mendapatkan pengalihan perhatian sehingga penderita tidak melamun.

\section{Upaya Pencegahan Kekambuhan dengan Pengenalan Gejala Awal Skizofrenia}

P1 :"...biasenye eee...pandangan mata tajam, susah disuruh, tidak menurut kalau disuruh"

P2 :"...geyelah die dah mule melamun, pun dah melamun die kite tegurek ee daan maok bunyi aaa dah mulai dah die ye, makan pun kurang kadang sehari be ndak makan sama sekali, pun jak sehat tetap teratur die pagi tetap makan siang makan malam ape, pun daan makan ngopiii tolen sehari hari empat lima kali enak kali ngopi" 
P3 :"...menyendiri di kamar ndak maok keluar-keluar, di suruh ndak maok habis itu moodnye ndak stabil suke nak marah kalau disuruh suke nak bantah, terus di ajak ngomong kadang ndak nyambung "

P4 :"...ooh, mengenali... jadi kalau seperti mereka ni kadang kalau kambuh itu bingung kalau di kasih tau misalnye sapu di ruang tamu tapi tidak didulikan kadang ditempat lain yang disapu bingung, kadang senyum sendiri tertawa sendiri eee.. sulit untuk mandi itu dia kalau mudah kambuh" P5 :"...kadang mau pukul orang, ...lalu dia tidak mau minum obatnya"

Tema ini memiliki sub kategori yang tergabung dalam sebuah pernyataan yang diberikan oleh partisipan yaitu gejala positif dan gejala negatif dari kekambuhan skziofrenia. Pernyataan partisipan di atas merupakan pengetahuan keluarga dalam mengenali dan mengetahui gejala awal dari kekambuhan yang terjadi pada penderita skziofrenia.

\section{Beban Psikologis yang Dialami Keluarga}

P1 :"...ya harus sabar eee”, "Iya kalau misalnya dia apa ... agak bingung kadang kita juga terpengaruh kadang juga agak emosi"

P2 :"...rase sedih ade juak rase geram ade juak rase giye kan namenye kite" P3 :"...sedih ade gak pas die agek kambuh, jengkel ade gak rase ndak mampu ape buat jagenye"

P4 :"...cuma kadang kita agak emosi juga rasanya tapi walaupun emosi tapi bukan sekasar yang biasa dilakukan orang dipukul apa itu tidak”...." kadang kite pun agak kasar dikit dari segi komunikasi tapi kalau istilahnye secara tindakan tidak ada yang kasar" P5 :"...perasaan saya sih ya gimana lah ya namanya anak kita, kita juga merasa sedih"

Tema ini memiliki sub kategori yang tergabung dalam sebuah pernyataan yang diberikan oleh partisipan yaitu perasaan dan tindakan. Pernyataan pasrtisipan di atas menggambarkan beban psikologi yang dialami oleh partisipan. Partisipan mengatakan bahwa perasaan yang dialami partisipan berubah-ubah kadang sedih, dan kasian terkadang juga emosi dan jengkel. Selain itu partisipan juga mengatakan bahwa partisipan kadang juga agak kasar kepada penderita namun dalam segi komunikasi bahkan pernah merasa sudah tidak mampu lagi untuk menjaganya.

\section{Koping Keluarga Terhadap Stigma Sosial}

P1 :"...misalnya keluargamu ada seperti itu di olok-olok gimana perasaanmu, malu ndak. Akhirnya dia tidak ada melakukan seperti itu lagi" P3 :" ...kembali lagi kan udah takdirnya kan dia seperti itu yaa terima sajalah"

P4 :" ...perasaan kami sebagai keluarga ya memberikan pengertian kepada orang yang mengolok-olok die bahwa terjadi seperti itu bukan kemauan mereka kepada siapapun itu bisa terjadi, nah jadi tolong jangan di olok-olok dia misalnya kalau anda mengalami apa yang dia alami 
bagaimana perasaan anda jika di hina oleh masyarakat, menerima akhirnya.."

Tema ini tidak memiliki sub kategori. Pernyataan yang di atas merupakan cara keluarga dalam menerapkan koping terhadap stigma sosial yang diberikan masyarakat kepada penderita.

\section{PEMBAHASAN}

\section{Kasih Sayang Keluarga Sebagai Kunci Perawatan yang Efektif}

Cara perawatan yang diberikan oleh partisipan dalam penelitian ini adalah harus pelan tidak boleh kasar yang berarti pemberian perawatan haruslah dengan kelembutan. Makna yang dapat kita simpulkan dari kata tersebut adalah selama kita merawat pasien dengan skizofrenia di rumah haruslah sabar dengan cara pelan-pelan tidak boleh kasar karena, jika kita melakukan kekasaran kemungkinan besar yang akan terjadi adalah penderita akan lebih kasar lagi kepada kita sebagai keluarganya. Penelitian yang dilakukan oleh Fadil dan Mitra (2013) mendapatkan hasil tentang cara pemberian perawatan yang dilakukan oleh keluarga direkomendasikan untuk tidak menghadapi penderita dengan kasar karena bisa menyebabkan kondisi penderita semakin buruk ${ }^{15}$.

Berdasarkan hasil penelitian yang dilakukan pada beberapa partisipan didapatkan bahwa partisipan mengetahui beberapa peran yang harus dilakukan keluarga dalam merawat penderita, yaitu: menjaga penderita dengan baik, memberikan perhatian lebih dan memberi dukungan kepada penderita, namun ada satu hal yang sangat dipahami oleh keluarga adalah peran keluarga dalam menjaga kepatuhan minum obat bagi penderita. Keluarga harus selalu mengontrol dan memberikan obat sesuai resep yang sudah diberikan oleh pihak RSJ. Keluarga juga harus memahami bahwa minum obat dalam waktu jangka panjang sangat dibutuhkan oleh penderita guna mencegah kekambuhan.

Penelitian lain juga dilakukan oleh Emsley, Chiliza, Asmal dan Harvey (2013) mengatakan bahwa angka kekambuhan akan sangat tinggi jika pemberian obat tidak dilakukan dengan rutin atau bahkan dihentikan. Selain itu pemberian obat dengan jangka waktu yang lama sebelum penghentian tidak mengurangi resiko kambuh $^{6}$. Penelitian Kaunang, Kanine dan Kallo (2015) juga mengatakan bahwa pada penderita skizofrenia yang sudah keluar dari rumah sakit, tugas perawat digantikan oleh keluarga. Keluarga yang harus selalu mengawasi dan memastikan penderita minum obat dengan teratur serta membawa penderita untuk selalu kontrol ke poliklinik. Dampak yang akan terjadi jika penderita tidak rutin minum obat adalah kekambuhan ${ }^{16}$.

Penelitian yang dilakukan Dewi, Pratiwi \& Dewi (2016) mendapatkan hasil bahwa keluarga merupakan pemberi perawatan utama atau caregiver untuk mengambil keputusan terhadap pengobatan dengan membawa pasien berobat ke Rumah Sakit ataupun ke puskesmas terdekat sebagai upaya penyembuhan sehingga 
dapat mengurangi resiko kekambuhan pada penderita ${ }^{17}$.

Berdasarkan hasil penelitian dan observasi yang dilakukan, partisipan mengatakan bahwa partisipan selalu mempersiapkan dan selalu mengawasi penderita saat minum obat agar penderita tepat waktu minumnya, selain itu juga partisipan mengatakan bahwa partisipan selalu memberikan aktivitas ringan seperti menyapu, cuci piring dan lain-lain kepada penderita agar penderita bisa menjadi lebih baik.

Pemberian aktivitas merupakan sesuatu yang sangat penting untuk penderita, karena melalui aktivitas tersebut penderita dapat berolahraga, pikiran bisa teralihkan ke hal yang lebih baik dan yang paling dihindari adalah agar penderita tidak melamun. Pemberian aktivitas ini harus dilakukan secara rutin kepada penderita, sehingga dituntut ketelatenan untuk keluarga dalam memberikan dan mengarahkan aktivitas yang harus dilakukan oleh penderita dalam sehari-hari. Hal ini selaras dengan penelitian yang dilakukan oleh Hastuti dan Rohmat (2018) yang mendapatkan hasil bahwa pemberian aktivitas memang sangat diperlukan bagi penderita skizofrenia dalam pemberian keperawatan dengan tujuan untuk meningkatkan kemandirian penderita agar tidak selalu bergantung dengan orang lain ${ }^{18}$.

Penelitian lain yang dilakukan oleh Saria, Outwater, dan Malima (2014) mengatakan bahwa penderita skizofrenia harus diberi aktivitas atau pekerjaan agar penderita terlihat sibuk dan tidak memikirkan penyakit mental yang dideritanya, selain itu dengan melakukan aktivitas ini akan membuat penderita merasa telah meningkatkan harga diri mereka dan membantu mereka merasa bahwa mereka dapat menyumbangkan sesuatu kepada keluarga atau masyarakat ${ }^{7}$.

\section{Upaya Pencegahan Kekambuhan dengan Pengenalan Gejala Awal Skizofrenia}

Kekambuhan merupakan sesuatu yang sangat erat dengan penyakit skizofrenia. Seorang penderita dengan skzifrenia yang sudah dikatakan pulih akan berisiko tinggi untuk mengalami kekambuhan. Kekambuhan yang terjadi disebabkan oleh banyak hal seperti dukungan keluarga, kepatuhan dalam minum obat serta lingkungan.

Berdasarkan hasil penelitan didapatkan bahwa kekambuhan merupakan memburuknya keadaan penderita dari. Penderita yang mengalami kekambuhan akan mununjukkan tingkah yang sama seperti tingkah yang aneh seperti sebelumnya atau bahkan bisa menunjukkan tingkah yang lebih parah dari sebelumnya. Partisipan mengatakan bahwa sebagian besar kekambuhan dapat terjadi karena penderita tidak mengkonsumsi obat yang telah diberikan oleh pihak Rumah Sakit Jiwa. Saat penderita mengalami kekambuhan keluarga masih belum terlalu memahami tentang cara penanganannya, keluarga hanya mengetahui cara penangannya dengan diberikan obat dan langsung dibawa ke RSJ kembali. Hal ini disebabkan karena pengalaman masih belum mumpuni sehingga menyebabkan keluarga kebingungan 
jika dihadapkan dalam kondisi seperti itu.

Keluarga yang menjadi caregiver bagi penderita harus mampu mengenali jika terjadi kekambuhan pada penderita, karena dengan keluarga bisa mengenali kekambuhan pada penderita, keluarga bisa menentukan tindakan selanjutnya yang harus dilakukan. Hal ini sesuai dengan penelitian yang dilakukan oleh Azwar (2011), mengatakan bahwa informasi atau pengetahuan berpengaruh besar dalam perawatan sehingga bisa memunculkan opini dan kepercayaan pada keluarga, karena informasi yang didapat akan mempermudah seseorang untuk mempersepsikannya sehingga dapat dinilai secara langsung dari isi informasi tersebut hingga terwujud dalam suatu tindakan ${ }^{19}$.

Penelitian yang dilakukan oleh Hayani, Elita, \& Hasanah (2012) mengatakan bahwa pengetahuan tentunya sangat berperan penting, karena dengan memiliki pengetahuan yang baik mengenai skizofrenia, keluarga bisa memutuskan sikap apa yang dapat dilakukan untuk mengatasi masalah kesehatan yang diderita oleh penderita skizofrenia, selain itu pengetahuan keluarga dalam mengenali kekambuhan pada pasien skizofrenia juga akan bisa meningkatkan kemampuan keluarga dalam merawat penderita sehingga kemampuan kambuh dapat dicegah ${ }^{20}$.

Pengetahuan tentang perawatan skizofrenia ini menjadi salah satu faktor yang dapat menyebabkan kekambuhan. Penelitian yang dilakukan oleh Yaqin (2015) mengatakan bahwa semakin tinggi tingkat pengetahuan keluarga tentang skizofrenia, maka semakin berkurang frekuensi kekambuhan yang akan terjadi, begitu juga sebaliknya semakin rendah tingkat pengetahuan keluarga maka semakin tinggi frekuensi kekambuhan yang akan terjadi $^{21}$.

Penelitian yang dilakukan oleh Agustina dan Handayani (2017) tentang Kemampuan Keluarga Dalam Merawat Pasien Skizofrenia dengan Halusinasi mendapatkan hasil bahwa pengetahuan tentang perawatan skizofrenia memiliki hubungan dengan frekuensi terjadinya kekambuhan pada penderita skizofrenia $^{22}$.

\section{Beban Psikologis yang Dialami Keluarga}

Partisipan mengatakan merasa sedih dan kasian selama merawat merawat penderita, perasaan sedih ini disebabkan karena melihat keadaan penderita yang sangat memprihatinkan. Kondisi penderita yang mengalami skziofrenia terlihat bermacam-macam, ada yang mengalami defisit perawatan diri sehingga terlihat sedikit kotor dan bau, ada yang suka berteriak-teriak dan bahkan ada yang mengeluarkan ekspresi ketakutan.

Perasaan sedih yang dialami partisipan tersebut kadang harus dimiliki oleh keluarga selaku caregiver, karena dengan adanya perasaan sedih atau empati terhadap keadaan penderita akan mendorong partisipan untuk memberikan perawatan dengan sabar. Selain itu dengan adanya empati dari keluarga dapat memberikan motivasi tersendiri 
kepada keluarga untuk bisa memberikan perawatan dengan sebaik mungkin, namun selain dari perasaan sedih kadang juga timbul sifat jengkel, emosi dan marah-marah dalam memberikan perawatan kepada penderita. Perasaan tersebut muncul karena tingkah penderita yang kadang sulit untuk diarahkan, biasanya penderita melakukan perlawanan sehingga membuat keluarga menjadi emosi.

Kondisi psikologis keluarga juga sangat menentukan penderita akan sembuh atau bahkan mengalami kekambuhan. Penelitian yang dilakukan oleh Khaira dan Zulfitra (2017) mendapatkan hasil bahwa kondisi psikologis keluarga yang buruk akan menyebabkan kondisi penderita akan semakin cepat mengalami kekambuhan, semua ini disebabkan karena disaat ekspresi emosi keluarga yang tinggi akan memberikan tekanan kepada penderita sehingga membuat kondisi kesehatan akan memburuk $^{23}$.

Perawatan pada penderita skizofrenia diperlukan waktu yang sangat lama, sehingga tidak menutup kemungkinan keluarga yang berperan sebagai caregiver akan merasa bosan dan jenuh, sementara itu partisipan juga pernah emosi atau marah-marah serta rasa jengkel atau kesal terhadap pasien dikarenakan selama perawatan pasien tidak kooperatif selama menjalani perawatan yang dilakukan oleh keluarga.

Hal ini selaras dengan penelitian yang dilakukan oleh Dewi, Pratiwi \& Dewi (2016) yang mendapatkan hasil bahwa keluarga yang merawat penderita skizofrenia tidak dipungkiri akan mengalami rasa bosan dan jenuh atau bahkan merasa emosi, marahmarah, kesal dan jengkel karena tingkah atau respon yang diberikan oleh penderita susah untuk dikontrol dan diarahkan ${ }^{17}$. Selain itu penelitian yang dilakukan oleh Kartika, Wiarsih \& Permatasari (2015) dengan judul penelitian "Pengalaman Keluarga dalam Merawat Penderita Sakit Kronis" mendapatkan hasil bahwa kondisi psikologis keluarga yang menjadi caregiver akan mengalami perubahan, kadang akan merasa sedih, takut, emosi dan bahkan marah serta respons psikologis lain adalah perasaan menerima sebagai hasil dari respons adaptasi ${ }^{24}$.

Penelitian yang dilakukan oleh Fadli dan Mitra (2013) mengatakan bahwa pasien skizofrenia yang tinggal dalam lingkungan keluarga dengan ekspresi emosi yang kuat (highly expressed emotion) atau gaya afektif negatif secara signifikan lebih sering mengalami kekambuhan dibandingkan dengan yang tinggal dalam lingkungan keluarga dengan ekspresi emosi yang rendah (low expressed emotion) atau gaya afektif yang normal. Keluarga memperlihatkan emosi yang diekspresikan secara berlebih, misalnya klien sering diomeli atau dikekang dengan aturan yang berlebihan, kemungkinan pasien untuk kambuh akan semakin besar ${ }^{15}$.

Kondisi psikologis keluarga juga akan memberikan pengaruh terhadap kualitas perawatan yang diberikan keluarga kepada penderita, karena disaat kondisi psikologis keluarga dalam keadaan yang stabil maka 
kualitas pelayanan yang akan diberikan juga akan optimal, begitu juga sebaliknya jika kondisi psikologis keluarga dalam keadaan yang buruk maka akan menurunkan kualitas perawatan kepada penderita, sehingga akan meningkatkan resiko kekambuhan pada penderita skizofrenia.

Keluarga yang memberikan perawatan kepada penderita skziofrenia akan memiliki ketahanan psikis terhadap suatu kondisi yang sama. Hal ini selaras dengan penelitian yang dilakukan oleh Summerville and Atherley (2012) dalam jurnalnya berjudul Hope for family caregivers caring for family members with schizophrenia:

Adiscussion mendapatkan hasil bahwa anggota keluarga yang merawat penderita skziofrenia yang tidak kunjung pulih akan memiliki ketahanan karena adanya harapan yang kuat dalam diri mereka untuk kesembuhan penderita sehingga keluarga selalu melakukan apa yang memang menjadi cara mengatasi skziofrenia melalui edukasi yang diberikan oleh tenaga kesehatan $^{25}$.

\section{Koping Keluarga Terhadap Stigma Sosial}

Stigma sosial merupakan lingkungan yang sangat berpengaruh terhadap kesembuhan penderita selain dari dukungan keluarga. Stigma sosial ini bahkan menjadi salah satu faktor yang dapat menyebabkan terjadinya kekambuhan dikarenakan stigma sosial yang negatif. Stigma sosial ini bukan hanya berdampak ke penderita skizofrenia saja, namun bahkan ke seluruh anggota keluarga sehingga yang ditakutkan anggota keluarga yang menjadi caregiver akan mengalami tekanan dan bisa mengalami stress karena stigma sosial.

Stigma sosial yang buruk akan menyebabkan keluarga menjadi malu karena keberadaan anggota keluarga yang mengalami skziofrenia. Perasaan malu yang dialami oleh keluarga sebagai caregiver akan menyebabkan kemunduran perawatan bagi penderita skzifrenia, oleh karena itu penelitian yang dilakukan oleh Nasriati (2017) mengatakan bahwa keluarga harus memiliki koping yang baik terhadap keadaan yang dialami, karena jika keluarga mengalami koping yang baik maka hal tersebut akan meningkatkan kualitas pelayanan pada penderita skizofrenia. Namun, jika koping keluarga buruk terhadap stigma yang berlaku maka akan menyebabkan hambatan bagi keluarga dalam memberikan perawatan kepada penderita skziofrenia di rumah seperti keterlambatan dalam pengobatan ${ }^{26}$.

Berdasarkan hasil penelitian yang dilakukan pada semua partisipan didapatkan bahwa sebagian besar awalnya partisipan selaku pihak keluarga merasa malu karena mempunyai keluarga yang mengalami skziofrenia, sehingga berpengaruh dalam proses perawatan yang diberikan keluarga. Namun, semua itu tidak berlangsung lama seperti yang disebutkan oleh partisipan 5 bahwa beliau awalnya malu karena mempunyai anak dengan skizofrenia, semakin lama beliau tidak merasa malu lagi karena beliau mengetahui 
bahwa banyak orang diluar sana yang mengalami skziofrenia, bahkan ada tetangga partisipan yang anaknya juga mengalami skizofrenia, dikarenakan mereka mengalami kondisi dan peran yang sama sebagai caregiver, maka mereka saling berbagi informasi terkait cara perawatan penderita skziofrenia.

Penelitian yang dilakukan oleh Wijanarko dan Ediati (2016) yang mendapatkan hasil bahwa masalah yang akan ditemui pihak keluarga dalam merawat pasien skzifrenia adalah respon masyarakat. Keluarga akan merasa malu karena memiliki anggota keluarga yang mengalami skziofrenia, sehingga memungkinkan keluarga untuk mengalami kondisi psikologis yang buruk. Hal ini berarti keluarga harus menerima penderita sebagai anggota keluarganya sehingga keluarga bisa menciptakan lingkungan yang baik bagi penderita ${ }^{27}$.

Pengaruh lingkungan atau stigma sosial selaras dengan penelitian yang dilakukan oleh Setsuko (2012) yang menyebutkan bahwa stigma yang diperoleh keluarga dengan skizofrenia adalah adanya penolakan terhadap masyarakat sekitar, lingkungan sekitar menganggap pasien skizofrenia itu berbahaya sehingga mereka memilih untuk menghindarinya, bahkan tidak ingin berada dalam satu lingkungan dengan keluarga yang memiliki anggota keluarga yang menderita skizofrenia $^{28}$.

Berdasarkan hasil penelitian yang dilakukan partisipan mengaku bahwa lingkungan sekitar sudah cukup kooperatif, sehingga mereka merasa diterima dan tidak dikucilkan, hal tersebut dapat terjadi karena lingkungan sekitar keluarga sudah mengetahui serta memahami mengenai penyakit yang diderita pasien sehingga lingkungan merasa dapat menerima hal tersebut. Selama merawat keluarga mengalami perubahan pada spiritual mereka, pada dasarnya beban fisik maupun emosional dapat dirasakan oleh setiap caregiver, namun karena sikap penerimaan diri yang keyakinan kesembuhan yang dimiliki oleh keluarga dapat mengatasi setiap proses kehidupan selama merawat penderita skziofrenia.

Hal ini selaras dengan penelitian yang dilakukan oleh Maghfiroh dan Khamida (2015) yang mendapatkan hasil bahwa jika penderita mampu berinteraksi secara baik maka akan bermanfaat bagi diri sendiri ataupun orang lain. Interaksi sosial bermasyarakat bagi penderita dapat membantu dalam meningkatkan hubungan sosial di lingkungan sekitar rumah sehingga bisa memunculkan stigma yang positif bagi penderita ${ }^{29}$.

\section{SIMPULAN DAN SARAN}

Berdasarkan hasil penelitian yang dilakukan didapatkan 4 tema yang menjadi titik perhatian peneliti, yaitu kasih sayang keluarga sebagai kunci perawatan yang efektif yang terdiri dari 3 kategori yaitu kelembutan, kontrol obat dan ketelatenan, tema yang kedua adalah upaya pencegahan kekambuhan dengan pengenalan gejala awal skizofrenia yang terdiri dari 2 kategori yaitu gejala positif dan gejala negatif, tema yang ketiga adalah beban psikologis yang dialami keluarga yang terdiri dari 2 kategori yaitu perasaan 
dan tindakan dan tema yang keempat adalah koping keluarga terhadap stigma sosial. Pengalaman keluarga sangat berarti dalam meningkatkan kualitas hidup pasien skizofrenia dan untuk mengurangi resiko terjadinya kekambuhan. Kasih sayang yang diberikan keluarga dalam merawat penderita ternyata memberikan dampak yang sangat baik bagi penderita, karena dengan kasih sayang itu dapat membuat penderita merasa lebih baik.

Penelitian selanjutnya diharapkan perlu melakukan penelitian lebih lanjut baik penelitian kualitatif maupun kuantitatif dengan tujuan untuk menggali secara lebih mendalam tentang pengalaman keluarga. Peneliti selanjutnya diharapkan dapat melakukan penelitian dengan menggunakan metode FGD (Forum Group Discussion) agar partisipan bisa lebih enak dalam sharing pengalamannya dalam merawat anggota keluarga yang mengalami skziofrenia. Peneliti yang menggunakan penelitian kualitatif dengan metode in-depth interview diharapkan agar lebih sering melatih diri untuk melakukan wawancara, sehingga dapat mengurangi kekakuan pada saat pengambilan data dan dapat menggali infomasi lebih banyak dan lebih dalam lagi.

Pemberian informasi dan edukasi kepada keluarga tentang bagaimana cara merawat anggota yang mengalami skziofrenia di rumah merupakan sesuatu yang wajib dilakukan oleh perawat atau tenaga kesehatan lainnya terutama keperawatan jiwa, agar keluarga dapat memberikan perawatan kepada penderita dengan baik dan benar di rumah, sehingga resiko kekambuhan bisa dicegah, untuk menjaga kondisi kesehatan penderita diharapkan perawat, puskesmas dan keluarga untuk selalu mengawasi dan memberikan perawatan kepada penderita skizofrenia.

\section{DAFTAR PUSTAKA}

1. DINKES. Profil Kesehatan Provinsi Kalimantan Barat Tahun 2016. Pontianak: Dinas Kesehatan. 2016

2. Melano, R. K. Pasien Sakit Jiwa di Kalimantan Barat Capai 5 Ribu Orang. Singkawang: Tribun Pontianak. 2018.

3. Riset Kesehatan Dasar. Hasil Utama Riskesdas 2018. Kementerian Kesehatan Badan Penelitian dan Pengembangan Kesehatan. 2018.

4. Taufik, Y. Hubungan Dukungan Keluarga dengan Tingkat Kekambuhan pada Pasien Skizofrenia di Poliklinik Rumah Sakit Jiwa Grhasia DIY. Jurnal Keperawatan Yogyakarta. 2014.

5. Haque, A. A., Kamal, A. K., Laila, Z. D., Laila, L., Ahmed, H. U., \& Khan, N. M. Factor Associated with Relaps of Schizophrenia. Bang J Psychiatry. 2017, 59-63.

6. Emsley, R., Chiliza, B., Asmal, L., \& Harvey, B. H. The Nature of Relaps in Schizophrenia. BMC Psychiatry. 2013, 1-8.

7. Sariah, A. E., Outwater, A. H., \& Malima, K. I. Risk and Protective Factors for Relaps Among Individuals with Schizophrenia: A 
Qualitative Study in Dar es Salaam, Tanzania. BMC Psychiatry. 2014, 1-12.

8. Ulia, A. Analisis Faktor-faktor yang Berhubungan dengan Kekambuhan Klien Skizofrenia di Wilayah Kerja Puskesmas Kumun Debai Kota Sungai Penuh Jambi. Jurnal Universitas Andalas. 2016.

9. Gitasari, N., \& Savira, S. I. Pengalaman Family Caregiver Orang Dengan Skizofrenia . Character. 2015, 1-8.

10. Ayudia, L., \& Nawangsih, E. Studi Deskriptif Kualitas Hidup pada Caregiver Pasien Orang dengan Skizofrenia di RSUD Soreang. Prosiding Psikologi. 2017, 468474.

11. Farkhah, L., Suryani, \& Hernawati, T. Faktor Caregiver dan Kekambuhan Klien Skizofrenia. JKP. 2017, 37-4

12. Sari, F. S. Dukungan Keluarga Dengan Kekambuhan Pada Pasien Skizofrenia. Jurnal Pembangunan Negeri. 2017, 1-18.

13. Rafiah, I., \& Sutharangsee, W. Review: Burden on Family Caregivers Caring for Patients with Schizophrenia and Its Related Factors. Nurse Media Journal of Nursing. 2011, 29-41.

14. Felicia, G. Self-Assessment of Functional Ability in Schizophrenia: Milestone Achievement and Its Relationship to Accuracy of Self-Evaluation. Psychiatry Reseacrh, doi: 10.1016/j.psychres.2013.02.035

15. Fadli, S. M., \& Mitra. Pengetahuan dan Ekspresi Emosi Keluarga serta Frekuensi Kekambuhan Penderita
Skizofrenia. Jurnal Kesehatan Masyarakat Nasional. 2013, 466470.

16. Kaunang, I., Kanine, E., \& Kallo, V. Hubungan Kepatuhan Minum Obat dengan Prevalensi Kekambuhan pada Pasien Skizofrenia Yang Berobat Jalan di Ruang Poliklinik Jiwa Rumah Sakit Prof Dr. V. L. Ratumbuysang Manado. Ejournal Keperawatan. 2015, 1-7.

17. Dewi, E. P., Pratiwi, A., \& Dewi, E. Pengalaman Keluarga Dalam Merawat Pasien Skizofrenia Tak Terorganisir Di Rumah Sakit Jiwa Daerah Surakarta. Publikasi Ilmiah. 2016, 1-13.

18. Hastuti, R. Y., \& Rohmat, B. Pengaruh Pelaksanaan Jadwal Harian Perawatan Diri Terhadap Tingkat Kemandirian Merawat Diri Pada Pasien Skizofrenia Di Rsjd Dr. Rm Soedjarwadi Provinsi Jawa Tengah. GASTER. 2018, 177-190.

19. Azwar, S. Penyusunan Skala Psikologi. Yogyakarta: Pustaka Pelajar, 2011.

20. Hayani, L., Elita, V., \& Hasanah, O. Gambaran Pengetahuan Keluarga Tentang Cara Merawat Pasien Halusinasi Di Rumah. Prodi Keperawatan Universitas Riau. 2012, 1-6.

21. Yaqin, T. F., Widodo, A., \& Zulaicha, E. Hubungan Pengetahuan Keluarga Tentang Tanda Dan Gejalskizofrenia Paranoid Dengan Upaya Mencegah Kekambuhan Pasien Di Rsjd Surakarta. 2015, 1-17. 
22. Agustina, N. W., \& Handayani, S. Kemampuan Keluarga Dalam Merawat Pasien Skizofrenia Dengan Gejala Halusinasi . URECOL. 2017, 439-444.

23. Khaira, N., \& Zulfitra, D. Pengaruh Dukungan Keluarga Terhadap Kekambuhan Pasien Gangguan Jiwa Di Wilayah Kerja Puskesmas Idi Rayeuk Kabupaten Aceh Timur. 2017, 42-56.

24. Kartika, A. W., Wiarsih, W., \& Permatasari, H. Pengalaman Keluarga Dalam Merawat Penderita Sakit Kronis. Jurnal Keperawatan Indonesia. 2015, 51-58.

25. Summervile, C. a. Hope For Family Caregivers Caring For Family Members With Schizophrenia: A Discussion, 2012.
26. Nasriati, R. Stigma Dan Dukungan Keluarga Dalam Merawat Orang Dengan Gangguan Jiwa (ODGJ). Jurnal Ilmiah Ilmu-ilmu Kesehatan. 2017, 56-65.

27. Wijanarko, A., \& Ediati, A. Penerimaan Diri Pada Orangtua Yang Memiliki Anak Skizofrenia . Jurnal Empati. 2016, 424-429

28. Setsuko, H. Family Caregivers of People with Schizophrenia in East Asian Countries,Schizophrenia in the 21st Century. InTech. 2012.

29. Maghfiroh, L., \& Khamida. Peran Keluarga Dalam Peningkatan Kemampuan Interaksi Sosial Bermasyarakat Klien Skizofrenia Pasca Perawatan Di Rumah Sakit. Jurnal Ilmiah Kesehatan. 2015, 104-113 
